\title{
Organizational Construction of the Classroom Language "Effective and Reasonable"-Take the Classroom Teaching of Sino-foreign Cooperation School as an Example
}

\author{
Tan Yi \\ Insurance Professional College, Hunan, Changsha, 410114
}

Keywords: classroom language; "effective and reasonable"; organizational construction

\begin{abstract}
Daily course development requires teachers to use texts, language and teaching tools to teach students the knowledge and technology. As an important knowledge information transmission tool, teachers organize and conduct language exchanges in a classroom environment, which plays an important part in promoting classroom teaching in Sino-foreign cooperative schools. At present, teachers' cognitive level of teaching language is not enough. Using of invalid classroom language limits the effect of class classroom teaching. How to use effective classroom language has become the main content of this paper.
\end{abstract}

\section{Introduction}

The development of Sino-foreign cooperation in running schools has gone through more than a decade, but from the perspective of theoretical research, the number of related studies is insufficient. Systematic research on the language of the course and the teaching model of the professional curriculum is even rarer. As the cooperation and exchanges between China and foreign countries continue to increase, the requirements for improving the effectiveness of Chinese-foreign cooperation in running schools are also increasing. In the teaching process, harmonious organization of language is the key. Teachers' good language organization ability directly determines the teaching effect, and good language expression is the basic ability of teachers to enhance teaching quality.

\section{An Overview of the "Effective and Reasonable" Classroom Language}

\section{1 "Effective and Reasonable" classroom language}

In 'School of Learning', it is said that "there are a good thing teachers who make people follow the sound. Good teachers, and people follow their ambitions' Thus, from ancient time till present, one of the core concepts of Chinese education is that we should always learn and train teachers' language. Training in grasping knowledge ability. The teacher's classroom language mainly refers to the teacher's organization of classroom teaching activities, through various techniques and methods, to develop information and emotional communication. The application of classroom language enables teachers to effectively transfer knowledge and technology to students. In this process, teacher language is actually an important medium for teachers to transmit knowledge information. It is equally a working term in the education industry. By using classroom language, teachers can establish a bridge between teaching and learning. Makomako also said: 'If the language of teaching is unreasonable, the effect may be 20 times worse.'

It can be observed that the "Effective and Reasonable" classroom language is a language skill and method that teachers can achieve according to the actual situation and needs of the classroom. As an essential weapon for teachers to carry out teaching, its effectiveness is crucial. At the same time, the use of effective classroom language can better enhance the classroom effect and form a good interaction between teachers and students 


\subsection{Class language type division}

\subsubsection{Class organization language}

In the process of organizing and constructing the class, teachers will design unique links and steps to complete the class guidance for students. Form of such kind of language is relatively fixed, belonging to one of the important forms of the teacher's class language type which needs to run through the entire class.

\subsubsection{Class explanation language}

Such languages are more common in traditional classes. Teachers use lecturing language to convey the information and knowledge to students, and explain and analyze the knowledge system and content that need to be presented, which facilitates students to fully understand the knowledge imparted.

\subsubsection{Class communication language}

Such language emphasizes communication between teachers and students, which is an essential tool for effective interaction between students and teachers, and can ensure that students are willing to accept the content expressed by teachers.

\subsubsection{Class evaluation language}

Use of class evaluation language is also an important supplement in teaching. Teachers need to evaluate students' performance according to students' class performance, including procedural evaluation language and summative evaluation.

\section{Unreasonable Use of Class Language}

\subsection{Unreasonable content of class language}

First, the class language content lacks integrity. Preciseness is absent in some teachers' class language. They only use a few words in one sentence. Instead, they use "this" and "that" instead. This will lead students to misunderstand, even the whole content.

Secondly, there are many arbitrariness in the classroom, and the logic of the classroom language is seriously insufficient. The textbooks have not been able to conduct in-depth thinking, and the relevant textbooks have not been able to go deeper. Therefore, problems and the inevitable lack of logic and accuracy.

Again, the language content of the class has too much and too complicated. Teacher's language training directly affects the teaching effect. If the classroom language uses too much discourse, the students will be confused and unable to capture effective information, which will make students' divergent thinking unable to fully play.

\subsection{The problem of classroom language form}

The voice is inaccurate, and basic language needs are understandable and understandable. Therefore, dialects should not be used instead of Mandarin. Otherwise the teaching effect will be reduced.

Speed of speech and tone also affects classroom teaching. Improper speed of speech and intonation will involve students' attention, making it impossible for students to focus on learning.

Teacher language lacks emotion, is too blunt, and students cannot form emotional projections in the learning process, which in turn will have a negative effect on student learning.

\section{Construction of "Fair and Reasonable" Organization Based on Chinese-foreign Cooperation in Running Schools}

\section{1 "The reasonableness" of classroom language}

First of all, teachers should establish a scientific and healthy learning concept, devote to a 
lifelong learning; on the one hand, they should respond to the school's centralized training requirements, continuously enrich their knowledge structure and improve their language and cultural competence. On the other hand, it is also necessary to strengthen the ability of professional knowledge terms from its own characteristics, and regard themselves as "professionals" and "living persons", constantly enriching and perfecting themselves so that they can establish a good image in the minds of their students.

Secondly, prepare fully before class, study the contents of teaching materials, combine diversified teaching resources, clarify the content of textbooks, and grasp the relationship between teaching difficulties and knowledge. Understand the content of the course of what has to be explained and what needs to be ignored. This can help teachers to improve language logicality and accuracy. Classroom language should get rid of arbitrariness and stick to the target.

Thirdly, as the dominant in the classroom, the inappropriate use of the teacher's language may weaken the effect on students' absorption of knowledge.

Blur the content of the class, therefore, teachers need to be able to grasp the main content of the classroom, teachers should focus on professional knowledge, all teaching language serve for it, to avoid the unreasonable use of language, so that students' thinking ability can be further improved.

Finally, a reasonable language is also a vivid language. A good classroom language must be a judicious language, and it should be a specific and vivid language. Such a linguistic approach can lead students to have the desire to learn and burn up their enthusiasm for learning. It is visualized and interesting for boring content. Such requirements require teachers to not only have the ability to analyze knowledge, but more excellent language control ability and vividly convey knowledge, all of these will make the teaching process more interesting.

\subsection{The "reasonableness" of classroom language}

First of all, students in the Sino-foreign cooperative school cannot use fluent Mandarin. However, teachers are required to spread Mandarin and help students with different levels of knowledge. To this end, teachers need to constantly insist on their own form and use the standard language as much as possible.

Secondly, the use of language should always be full of passion, language should be more appealing and influential, too fast speech speed may be unacceptable, and slower rhythm may lead to students' inattention. Teachers should be able to grasp the rhythm of language in teaching, so that students can be more attentive.

Thirdly, the tone of the classroom language should be properly used, and the tone needs to be moderates appropriately in the course of the course, so that the level is different, the size is different, and the student's attention is always caught.

Finally, the emotional direction is clear. The use of the language in the classroom should be affirmative, and the students' understanding or thinking should be given first and affirmation, and then help the students to improve and guide them.

Abandon the reproaches of the students. More use of encouraging language to help students build confidence. Appropriately guide students to develop continuous enthusiasm in the process of learning.

\subsection{Realization of role transformation}

In the past, teachers were dominant in the classroom. Students could not get the right to speak in such a classroom environment, nor was it conducive to students forming self cognition and thinking. To this end, we should reverse this "Teacher centered" situation so that students can speak. One of the functions of teachers' classroom language is communication with students. The rationality of teachers' classroom language is a mixture of students' language and ideas.

\section{Conclusion}

In summary, the "fair and reasonable" organizational teaching language can help teachers to complete the communication of classroom teaching content and realize the transmission of 
knowledge and information. Teaching language can largely reflect the development and reform of teachers' ideological consciousness in the development of new curriculum reform. In the face of the new curriculum reform background, teachers need to further improve their professionalism, improve their language control ability, and master more and more effective language skills. Only in this way can we continuously innovate teaching concepts and ultimately achieve rapid development.

\section{References}

[1] Zhu Minhua.Beyond the classroom - a new concept of independent language learning [J].Higher education exploration, 2017(05):57-61.

[2] Wang Shanling. The Status Quo and Countermeasures of Classroom Teaching Language in Primary Schools [J]. Science and Education Wenhui (mid-season), 2015(09):152-153.

[3] Shang Ruihua.An Analysis of the Optimization of Chinese Teachers' Classroom Language Art [J].Journal of Tonghua Teachers College, 2014, 34(01):142-144.

[4] ZhangJing. On the Optimization of the Language Environment in Spoken Language Classroom [J].Technology information, 2014(21):790-791.

[5] Wang Junxin. Teacher's Language Features and Roles in Second Language Classroom [J]. Journal of Jinan University (Social Science Edition), 2014(S1):41-42. 